\title{
Aerosol Optical Depth of MODIS Imagery over Bright Coastal Water: A Regression Technique
}

\author{
Abd Rahman Mat Amin \\ Faculty of Applied Science \\ Universiti Teknologi Mara, Kampus Kuala Terengganu \\ 21080 Kuala Terengganu, Terengganu, Malaysia \\ Tel: 60-96175-255Ｅ-mail:abdra401@tganu.uitm.edu.my
}

Khiruddin Abdullah

School of Physics, Universiti Sains Malaysia, Minden, 11080 Pulau Pinang, Malaysia

Tel: 60-46-532-477Ｅ-mail: khirudd@usm.my

Mohd Rivaie

Faculty of Science Computer and Mathematic

Universiti Teknologi Mara, Kampus Kuala Terengganu

21080 Kuala Terengganu, Terengganu, Malaysia

Tel: 60-96-175-255

\begin{abstract}
The contribution of sediment and bottom reflectance in the MODIS imagery over bright coastal water contaminate visible and near infrared channels. This contribution leads to the saturation in the ocean color channels and error in the MODIS derived product over that areas. The saturation in the ocean color channels lead to no aerosol optical depth (AOD) retrieved by MODIS algorithm over very turbid areas. The sediment contributions will increase the reflectance in the visible and near infrared channel that is used in the MODIS aerosol algorithm. This area is then masked using sediment masking algorithm. In this paper, a simple method to estimate the AOD over bright coastal water with high sediment and bottom reflectance contributions is proposed. The first seven MODIS solar channels centered at $0.47,0.55,0.66,0.86,1.24,1.64$ and $2.13 \mu \mathrm{m}$, originally designed for remote sensing over land and cloud properties have been utilized in this study. The algorithm is based on the excess reflectance at $0.55,0.66$ and $0.87 \mu \mathrm{m}$ wavelength using the power law model that can be associated to the presence of sediment. The excess value of the reflectance is discarded, to obtain the atmospheric contribution in the data. Aerosol contribution over bright coastal water areas is then compared with AOD of $0.869 \mu \mathrm{m}$ using regression technique. This study shows that the AOD and aerosol retrieved are in high correlation with $\mathrm{R}$ is greater than 0.90 . The AOD map from the applications of the algorithm were constructed and extrapolated for the saturated channels areas. The sample result of AOD map from several MODIS datasets acquired over the Gulf of Martaban is presented.
\end{abstract}

Keywords: MODIS, Remote sensing, Aerosol optical depth, Sediment, Turbid water

\section{Introduction}

At present satellite remote sensing of ocean colour is the only way to measure synoptically wide area of ocean properties such as chlorophyll patterns, sea surface temperature, phytoplankton abundance, distribution of suspended particulate matter and absorption by coloured dissolved organic matter. Imaging spectrometry has important applications in a variety of fields, including mineral explorations, vegetation studies, and coastal monitoring. Since mid 1980's, the concepts of imaging spectrometry and hyperspectral imaging have become increasingly popular. The Moderate Resolution Imaging Spectroradiometer (MODIS) and Sea-viewing Wide Field-of-view Sensor (SeaWiFS) have provided a view of chlorophyll patterns and ocean biospheres on global scales by using the advanced atmospheric correction algorithm for data processing. High quality ocean color products for the global open oceans have been produced by both SeaWiFS and MODIS (McClain et al., 2004; Bailey \& Werdell, 2006; Wang \& Shi, 2005). Researchers and scientists around the world have used this data to study and understand ocean physical, optical, and biological changes and their effects on climatic processes. The current SeaWiFS/MODIS algorithm had implemented a method to account for the NIR ocean contributions, 
based on a model of the spectral shape for particle backscattering coefficient in coastal waters (Stumpf et al., 2003; Wang \& Shi, 2007). Over the turbid ocean waters, however, there are still significant errors in the satellite-derived ocean color products due to model limitations for the complex turbid waters (Wang \& Shi, 2007).

In order to get useful information of the land and ocean biosphere over the world, the atmospheric absorption and scattering effects in the MODIS imagery must be removed. This process is known as atmospheric correction. Two main steps involved in the processing of ocean color satellite data are the atmospheric correction to remove the atmospheric contribution to the radiance measured by the satellite sensor and the use of bio-optical algorithms that relate water leaving radiance to the water constituents (D'Sa et al., 2002). Currently, NASA standard ocean color products have been routinely derived using the two MODIS near infrared (NIR) channels $(0.75$ and $0.87 \mu \mathrm{m})$ for atmospheric correction (Gordon \& Wang, 1994; Gordon, 1997). The atmospheric aerosols information is derived from channels centered near $0.66,0.75$, and $0.86 \mu \mathrm{m}$, where the water leaving radiances are close to zero. The aerosol information is derived by extrapolation of the near infrared to the visible part of the spectrum. Water leaving reflectance obtained is then used as an input to retrieve ocean color parameter.

The fact that suspended sediments will increases the radiance emerge of the water surface in the visible and near infrared region of the electromagnet spectrum has been made since late 1970's (Ritchie et al., 1976). Many researches that encountered a large range $\left(0-200 \mathrm{mgl}^{-1}\right)$ of suspended sediment concentration have found a curvilinear relationship between suspended sediments and radiance or reflectance (Ritchie et al., 1976, 1990; Curran \& Novo, 1988). This is because the amount of reflected radiance tends to saturate the respected channels used for detection as the suspended sediment concentrations increase. The point of saturation is wavelength dependent, with the shorter wavelength channels saturating at lower concentrations (Ritchie \& Cooper, 1988). The present of high sediment concentration over bright coastal water will not only saturate the MODIS ocean channel but also contribute to the systematic error in MODIS level 2 oceans and atmosphere product.

Numerous investigators shows that the atmospheric correction algorithm that currently apply for MODIS operational works well over case 1 water, whereas phytoplankton is the dominant water constituent but can give invalid results over brighter coastal waters or case 2 water (Gao et al., 2007; Wang \& Shi, 2005). The impact of this error lead to the large errors in the MODIS derived ocean color products (Wang et al., 2007; Hu et al., 2000). High concentrations of organic and inorganic suspended matter in case 2 waters may cause the water leaving signal in the visible and (0.4-0.75) and near infrared $(0.865$ and $0.950 \mu \mathrm{m})$ to be significantly greater than zero (Morel and Prieur, 1977; D'Sa , 2002; Arnone et al., 1998; Hu et al., 2000, 2001). As a result, the aerosol optical thickness that is derived from this signal in the near infrared, may be over estimated and further propagated to an over correction in the visible part of the spectrum (D'Sa , 2002). The other reason is the ocean color channels $(0.488,0.531$, and $0.551 \mu \mathrm{m})$ often saturated over bright coastal waters (Gao et al., 2007). Atmospheric correction algorithms that currently apply to multichannel remote sensing for open ocean regions in order to retrieve water leaving radiances cannot easily be modified for retrievals over turbid coastal waters (Gao et al., 2000). At present, operational products over optically shallow waters are not produced. Therefore, an improved atmospheric correction algorithm must be developed for the remote sensing of Case 2 waters (Gao et al., 2007; Hu et al., 2000; Li et al., 2003).

Numerous studies have been conducted to improve the atmospheric correction over turbid water area. Hu et al., (2000) have proposed a method to separate the water column reflectance from the total reflectance. With the assumption that the type of aerosol does not much vary over small spatial scales $(50-100 \mathrm{~km})$, the aerosol type from non turbid pixels then transferred to turbid pixels by using nearest neighbor method. Gao et al., (2000) have proposed a new algorithm that used lookup table with a vector radiative transfer code. Aerosol parameters are determined by a spectrum-matching technique that uses channels located at wavelengths longer than $0.86 \mathrm{~mm}$. The aerosol information is extracted back to the visible spectrum based on aerosol models during the retrieval of water-leaving radiances. A bright pixel modification method have been proposed by Lavender et al., (2005). Wang \& Shi (2007) have developed an algorithm based on combination of near infra red and short wave infra red channels.

In this paper a simple method to retrieve aerosol optical depth over bright coastal area is proposed. This algorithm is based on power law that utilized first 7 MODIS channels centered at $0.47,0.55,0.55,0.86,1.24$, 1.64 and $2.13 \mu \mathrm{m}$ originally designed for remote sensing over land and cloud properties. Sediments and bottom reflectance that have been detected by the algorithm is then discarded. Aerosol contribution is then compared to aerosol optical depth of $0.869 \mu \mathrm{m}$ using regression technique. The AOD map of $0.869 \mu \mathrm{m}$ over bright coastal areas is then constructed and extrapolated to the high sediment concentration area. 


\section{Ocean and atmospheric contribution in the MODIS channels}

MODIS channels 8-16 in the 0.4-0.9 $\mu \mathrm{m}$ spectral range are mainly designed for clear water (Case 1) remote sensing. The maximum reflectances for ocean color channels are significantly smaller than those for the land channels at similar wavelengths. Table 1 shows the characteristics of the MODIS channels (Li et al., 2007; King et al., 1992). This leads to the saturation of MODIS ocean color channels $(0.488,0.531$ and $0.551 \mu \mathrm{m})$ over high sediment concentration area ( $\mathrm{Li}$ et al., 2007). However, the ocean color channels have much higher signal-to-noise ratios and sensitive to darker surface compared to the land channels centered at similar wavelength. The saturation of these channels will contribute to the lost of geophysical and biological activities in the data. Channels with higher maximum reflectance can be utilized to overcome this circumstance. MODIS channels centered at $0.55,0.66,0.86,1.24,1.64$ and $2.13 \mu \mathrm{m}$, are commonly being used with aerosol retrieving algorithms, to derive aerosol models and aerosol optical depths. Water leaving reflectance in the aerosol algorithm is assumed to be zero in the short wave infrared channels $(1.24,1.64$, and $2.13 \mu \mathrm{m})$ due to strong absorption by the water mass (Gao et al., 2007; Gordon \& Wang, 1994; Li et al., 2003; Reza, 2008). The water leaving reflectance assumed to be zero (dark water) in these wavelengths region over case 1 and case 2. However, a significant oceans contribution has been detected in the near infrared channel $(0.86 \mu \mathrm{m})$. The water leaving reflectance at $0.55,0.66$ and $0.86 \mu \mathrm{m}$ channels were assumed to be the typical clear water or case 1 reflectance. On the other hand, the blue channel, $0.47 \mu \mathrm{m}$ is very sensitive to atmospheric molecular scattering, but less sensitive to the additional reflection by sediments ( $\mathrm{Li}$ et al., 2003). Over bright and shallow coastal water, sediments and shallow waters provide such unaccounted high reflectance and results for the systematic overestimation of the aerosol optical thickness ( $\mathrm{Li}$ et al., 2003).

The turbid water has significantly larger reflectance than the clear water. Over that area, the reflectance in visible even near infrared channels shows an increment. The differences between the case 1 and case 2 waters are located in the $0.4-0.7 \mu \mathrm{m}$ spectral range ( $\mathrm{Li}$ et al., 2003; Reza, 2008). The main contribution of the increment in the remote sensing image in these wavelength regions are sediment and bottom reflectance ( $\mathrm{Li}$ et al, 2003). The effect of sea floor on the reflected radiance even in the shorter region of the spectrum is minimal when suspended sediment concentration (SSC) is high enough (Reza, 2008). The penetration depths in clear water at the level of $90 \%$ light attenuation is as high as 40 meters for $0.55 \mu \mathrm{m}$ channel and as low as a millimeter for $2.13 \mu \mathrm{m}$ channel (Hu et al., 2000). This means that the higher values of SSC may limit the depth of penetration of $0.55 \mu \mathrm{m}$ channels to a few centimeters and increases the amount of scattering in this channel as a consequence (Hu et al., 2000; Reza, 1995).

Because of the small penetration depths of sunlight into the water for the longer wavelengths $(1.24,1.64$ and $2.13 \mu \mathrm{m})$, the possibility of the reflection by sea floor is negligible. The contribution of sediment in the reflectance of $0.47 \mu \mathrm{m}$ channel can also be neglected. As discussed above, the MODIS channels centered at 0.47 , $1.2,1.6$, and $2.1 \mu \mathrm{m}$ are mainly influenced by aerosol scattering and water vapor absorption and can be used to derive the atmospheric spectral power law. The $0.55-0.86 \mu \mathrm{m}$ channels measurements are influenced both by the aerosol and the sediments. The excess reflectance at $0.55-0.86 \mu \mathrm{m}$ beyond the power law (Li et al., 2003) values can be associated to the presence of sediments and used for their detection. The $0.55 \mu \mathrm{m}$ channel reflectance can be used to detect the present of sediment and sea floor due to the high penetration (up to $40 \mathrm{~m}$ ) in the clear waters area. Meanwhile, the $0.66 \mu \mathrm{m}$ channel is much suitable to discriminate the sediment reflectance and atmospheric contribution from the signal measured by the sensor.

\section{Data and study area}

MODIS Terra Level 1B (MOD021KM) and Ocean Color Level 2 products during the period of January 2008 to November 2008 have been used in this study. The MODIS Level 1B granule consists of calibrated radiances or reflectance. The Ocean Color Level 2 products that contain aerosol optical depth of $0.869 \mu \mathrm{m}$ channel can be downloaded from NASA Ocean Color website. The study area covers roughly the latitude range of $14^{0} \mathrm{~N}-18^{0} \mathrm{~N}$ and the longitude range of $94^{\circ} \mathrm{E}-98^{\circ} \mathrm{E}$ Gulf of Martaban is located at the northern Andaman Sea. Annually more than 350 million tons of sediment deposited into this area by the Ayerrarwady, Salween and Sittang rivers. Seafloor in the Gulf of Martaban and adjacent inner shelf is generally smooth whereas the outer shelf has a rough surface with relief of 2-20 m and has topographic features such as pinnacles, highs and valleys, buried channels and scarps. Surface suspended sediment concentrations (SSC) values in the Gulf of Martaban can be from less than $0.1 \mathrm{mg} \mathrm{l}^{-1}$ to over $500 \mathrm{mg} \mathrm{l}^{-1}$ (Ramaswamy, 2004). Figure 1 below shows the map of study area.

\section{Methodology}

Channels 1 to 7 L1B were extracted and then stacked with AOD of $0.869 \mu \mathrm{m}$ channel of Ocean Color level 2 products. Cloud and land were then masked by Ocean Color level 2 products. After cloud and land have been 
masked, the log-log graph for first seven MODIS channels was constructed. Three different regions based on visual inspection were classified. The three areas are, firstly aerosol and sediment free area, secondly the sediment free but contaminated by aerosol area and lastly the sediment area. The $0.47,1.24,1.64$ and $2.13 \mu \mathrm{m}$ channels are in line for the turbid water areas. The heightened in reflectance of $0.55,0.66$ and $0.86 \mu \mathrm{m}$ channels over turbid water areas in the remote sensing image are due to the contribution of sediment and bottom reflectance. The excess reflectance of $0.55,0.66$ and $0.86 \mu \mathrm{m}$ channels beyond the power law value will then be discarded. The sediment and bottom reflectance free image will then be compared with AOD of $0.869 \mu \mathrm{m}$ map using regression technique. Due to the saturation in the ocean channels, AOD map of $0.869 \mu \mathrm{m}$ will only be available in the regions with relatively low sediment contribution. In this study, only the pixels that are detected been influence by sediment with AOD of $0.869 \mu \mathrm{m}$ values was compared. The AOD map of $0.869 \mu \mathrm{m}$ is then constructed from the application of the algorithm and then extrapolated to the high sediment contribution areas.

\section{Result and discussion}

\subsection{Removal of sediment and bottom reflectance effects}

In this discussion, MODIS image acquired on 13 November 2008 and the reflectance of $0.55 \mu \mathrm{m}$ channel is used as an example. Figure 2 below shows an image of $0.55 \mu \mathrm{m}$ channel of the study area for the date of 13 November 2008. Three areas were selected and categorized based on visual inspection according to their conditions. Areas 1 is less turbid and was referred as clear water area. This indicates that the reflectance values from this area are small compare to the other two areas. The assumption that water will appears as dark in this channel over open ocean region is true in this study. Area 2 is visually influenced by aerosol and is referred as hazy area. They have higher reflectance value than those in area 1 and located in deep water region (greater than $40 \mathrm{~m}$ ) where the reflectance effects from sediment and bottom material were very small. Therefore these high reflectance water pixels are mainly caused by aerosol. The corresponding aerosol optical thickness (AOD) map (MODIS Level 2) distributed by NASA Ocean Color also indicated the presence of aerosol (AOD values 0.148 to 0.289 ) in these areas. Meanwhile, area 3 is visually turbid water areas with suspended sediment. This area shows apparently greenish to grayish color and high reflectance value.

Figure 3 below shows the histogram for the areas indicated in the Fig. 2 above. Three peaks have been identified at different reflectance values that represent three different areas in the scene. The first peaks with the lowest reflectance value indicate the clear water area. The second peak indicates the hazy area. The third peak represents the sediment influence area. The third peak exists due to the contribution of sediment reflectance in the data. This peak only exist in the coastal area that the contribution of sediment reflectance are strong. In the free sediment area the histogram only shows clear and hazy peak. The present of reflectance by sediment in the MODIS data over bright coastal water as shown above, contribute to the over estimating of aerosol optical depth over coastal area.

The comparisons between the spectral properties of regions with and without sediments are shown in Fig. 4 . Figure 4 show a typical log-log graph of the apparent reflectance against center wavelength of seven MODIS band for sediment free and sediment influence area. This figure was constructed by picking up a pixel in each region. Based on visualization, hazy area is influenced more by aerosol compared to clear area. The spectral reflectance for hazy area and clear area fitted well with power law formula line, which illustrated by the straight line of the graph. Spectral reflectances for clear area are lower than hazy area with steeper slope due to smaller aerosol concentration. The differences between the slopes are due to the contribution of aerosol.

In the sediment water area, the values of $0.55,0.66$ and $0.86 \mu \mathrm{m}$ reflectance are above the power law line. Increment reflectances in these channels are due to the effect of sediment in that area. Meanwhile, the 0.47, 1.24, 1.64 and $2.13 \mu \mathrm{m}$ reflectance fitted very well with the power law line. The reflectances in that area are higher in the grayish area compared to greenish area. This indicated that, grayish area contribute more reflectance than greenish area. After sediment effect have been discard from the image, the value of $0.55,0.66$ and $0.87 \mu \mathrm{m}$ channels will be fitted in line with four others channels. In order to validate this algorithm, the histogram for the three areas discussed above, was build in Fig. 1. This figure shows the third peak whereas represents the sediment reflectance peak that exists in the raw data was successfully removed. Figure 5(a) shows the image of 13 November 2008 before the sediment and bottom reflectance have been removed. Whitish color in the coastal area in this image indicated the present of sediment reflectance. Figure 5(b) shows the excess of reflectance contributed by sediment and bottom reflectance. Meanwhile, Fig. 5(c) shows an image after the excess reflectance has been removed. In this image, the whitish color in Fig. 5(a) that indicated the contribution by sediment and bottom reflectance was successfully removed. 


\subsection{Aerosol optical depth retrieval}

As shown in Table 1, the ocean channels have relatively low maximum reflectance compared to land/cloud channels. Over very turbid coastal water, these channels tend to saturate due to high reflectance contributed by sediment. Figure 6(a) show the $0.869 \mu \mathrm{m}$ AOD map of study area distributed by MODIS ocean color. In this map, the numbers of pixels have no value due to the saturation of ocean color channel. MODIS $0.55 \mu \mathrm{m}$ that is most influence by sediment compared to 0.66 and $0.87 \mu \mathrm{m}$ have been used in this technique. Furthermore, this channel could sense the presence of relatively low sediment concentration.

After sediment and bottom reflectance have been removed, the pixel is then used as an input in this study. Only pixels with AOD information and detected contaminated by sediment have been used in this technique. Pixel that carries no AOD value and detected as free from sediment contamination was masked. The numbers of pixels used in this study highly dependent on the degree of turbidity. The increase of turbidity leads to lot of pixel saturated. The other factor that influences the number of pixels available for this study is the presence of cloud. Several MODIS dataset have been used in this study. The AOD and aerosol retrieved are in high correlation $(\mathrm{R}>0.90)$. As an example the AOD and aerosol for the date mentioned above shows high correlation with $\mathrm{R}=0.95$.

Figure 6(b) shows an AOD of $0.869 \mu \mathrm{m}$ map for 13 November 2008 constructed by this algorithm. The map is constructed using extrapolation technique. The result shows quiet reasonable value with smooth transition of AOD value from clear water to turbid water areas.

\section{Conclusion}

A simple technique to retrieved aerosol optical depth over bright coastal water has been proposed. The method is based on the analyses of MODIS dataset above Gulf of Martaban. The regression of aerosol contribution of 0.55 $\mu \mathrm{m}$ with AOD of $0.869 \mu \mathrm{m}$ shows high correlation $(\mathrm{R}>0.9)$. The AOD obtained by this technique shows reasonable AOD value. Smooth AOD transition has been shown between clear and turbid water area. The AOD of $0.869 \mu \mathrm{m}$ proposed could be extrapolated to the other channel. The main strength of this technique is that, even in the saturated area, the AOD map can still be produced.

\section{Acknowledgment}

We would like to thank UiTM Kuala Terengganu and USM management for the support and encouragement. Our appreciation to MODIS and SeaDAS team for all the valuable data provided.

\section{References}

Arnone, R.A, Martinolich, P. Gould, R. W., Stumpf, R. \& Ladner, S. (1998). Coastal optical properties using SeaWiFS; Ocean Optics XIV, Kailua-Kona, Hawaii, USA

Bailey S. W., \& Werdell P. J. (2006). A multi-sensor approach for the on-orbit validation of ocean color satellite data products. Remote Sens. Environ. 102, 12-23.

Curran, P.J., \& Novo, E.M.M. (1988). The Relationship between Suspended Sediment Concentration and Remotely Sensed Spectral radiance. A Rev. J. Coastal Res., 4: 351-368.

D'Sa, E. J., Hu, C., Muller F. E. \& Carder K. L. (2002). Estimation of colored dissolved organic matter and salinity fields in case 2 waters using SeaWiFS: Examples from Florida Bay and Florida Shelf, Proc. Indian Acad. Sci. Earth Planet Sci., 111, 197- 207.

Gao, B.C., Montes, M.J., Li, R.R., Dierssen, H.M., \& Davis, C.O. (2007). An Atmospheric Correction Algorithm for Remote Sensing of Bright Coastal Waters Using MODIS Land and Ocean Channels in the Solar Spectral Region. IEEE Trans. Geosci. Remote Sens, 45, 6.

Gao B.C., Montes M.J., Ahmad Z. \& Davis, C.O. (2000). Atmospheric correction algorithm for hyperspectral remote sensing of ocean color from space. Appl. Opt., vol. 39, no. 6, pp. 887-896

Gordon H.R. \& Morel A. (1983). Remote assessment of ocean color for interpretation of satellite visible imagery. Edité par R.T. Barber, C.N.K. Mooers, M.J. Bowman and B. Zeitzschel, Lecture notes on coastal and estuarine studies, 4, $114 \mathrm{pp}$.

Gordon, H.R. \& Wang, M. (1994). Retrieval of water-leaving radiance and aerosol optical thickness over the oceans with SeaWiFS: A preliminary algorithm. Applied Optics, 33, 443-452.

Gordon, H.R. (1997). Atmospheric correction of ocean color imagery in the Earth Observing System era. Journal Geophysical Research, 102, 17,081-017,106. 
Hu, C., Carder, K.L. \& Muller, F.E. (2000). Atmospheric correction of SeaWiFS imagery of turbid coastal waters: a practical method; Remote Sens. Environ. 74 195-206

Hu, C., Carder, K.L., \& Muller, F.E. (2001). Erratum to Atmospheric Correction of SeaWiFS imagery over turbid coastal waters: A practical method. Remote Sens. Environ. 75447

King, M. D., Kaufman, Y. J., Menzel, W. P. \& D. Tanre. (1992). Remote sensing of cloud, aerosol, and water vapor properties from the Moderate Resolution Imaging Spectrometer (MODIS) . IEEE Trans. Geosci. Remote Sens., 30, 2-27.

Lavender, S. J., Pinkerton, M. H., Moore, G. F., Aiken, J. \& Blondeau-Patissier, D. (2005). Modification to the atmospheric correction of SeaWiFS ocean color images over turbid waters. Continental Shelf Research, 25, 539-555.

Li, R.R., Kaufman, Y.J., Gao, B., et al. (2003). Remote sensing of suspended sediments and shallow coastal waters. IEEE Trans. Geosci. Remote Sens. 41, 559.

Li, R.R., Kaufman, Y.J., Gao, B., \& Davis, C.O. (2007). An Atmospheric Correction Algorithm for Remote Sensing of Bright Coastal Waters Using MODIS Land and Ocean Channels in the Solar Spectral Region, IEEE Trans. Geosci. Remote Sens., 45, 0196-2892.

McClain C.R., Feldman, G.C. \& Hooker S. B. (2004). An overview of the SeaWiFS project and strategies for producing a climate research quality global ocean bio-optical time series. Deep-Sea Research Part II Topical Studies in Oceanography 51, 5-42

Mobley, C.D., Stramski, D., Bissett, W.P. \& Boss, E. (2004). Optical modeling of ocean water: Is the Case 1Case 2 classification still useful? Oceanogr., vol. 17, no. 2, pp. 60-67.

Morel, A., \& Prieur, L. (1977). Analysis of variations in oceran color. Limnol. Oceanogr, 22, 709-722.

Ramaswamy, V., Rao, P.S., Rao, K.H., Thwin, S., Rao, N.S., Raiker, V. (2004). Tidal influence on suspended sediment distribution and dispersal in the northern Andaman Sea and Gulf of Martaban. Marine Geology 208 (2004) 33-42

Reza M. M. (1995). Heat Transfer in the Upper Layer of the Ocean with Application in Satellite SST Measurements. A PhD Thesis, Physics Dept., James Cook University of North Queensland, Australia.

Reza, M.M. (2008). Assessment of Suspended Sediments Concentration in Surface Waters, Using Modis Images. American Journal of Applied Sciences 5 (7): 798-804.

Ritchie J.C., Schiebe F.R., and McHenry J.R. (1976). Remote Sensing of Suspended Sediments in Surface Water. Photogrammetric Engineering and Remote Sensing, 42: 1539-1545.

Ritchie J.C. \& Cooper, C.M. (1988). Comparison of Measured Suspended Sediment Concentration with Suspended Sediment Concentrations Estimated from Landsat MSS data. International Journal of Remote Sensing. 9: 379-387.

Ruddick, K.G., Ovidio, F. \& Rijkeboer, M. (2000). Atmospheric correction of SeaWiFS imagery for turbid coastal and inland waters. Applied Optics, 39, 897-912.

Siegel, D. A., Wang, M., Maritorena, S. \& Robinson, W. (2000). Atmospheric correction of satellite ocean color imagery: the black pixel assumption. Applied Optics, 39, 3582-3591.

Stumpf, R. P., Arnone, R. A., Gould, R. W., Martinolich, P. M., \& Ransibrahmanakul, V. (2003). A partially coupled ocean-atmosphere model for retrieval of water-leaving radiance from SeaWiFS in coastal waters. In S. B. Hooker \& E. R. Firestone (Eds.), NASA Tech. Memo. 2003-206892SeaWiFS Postlaunch Technical Report Series, Vol. 22. (pp. 51-59) Greenbelt, Maryland: NASA Goddard Space Flight Center.

Wang, M. \& Shi, W. (2005). Estimation of ocean contribution at the MODIS near-infrared wavelengths along the east coast of the U.S.: Two case studies. Geophysical Research Letters, 32, L13606. doi:10.1029/12005GL022917

Wang, M., Tang, J. \& Shi, W. (2007). MODIS-derived ocean color products along the China east coastal region. Geophysical Research Letters, 34, L06611. doi:10.1029/2006GL028599

Wang, M. \& Shi, W. (2007). The NIR-SWIR combined atmospheric correction approach for MODIS ocean color data processing. Optics Express, 15, 15722-15733. 
Table 1. Main characteristics of MODIS land and ocean color channels in the visible and near infrared spectral region.

\begin{tabular}{|c|c|c|c|c|}
\hline Primary use & Channels & Bandwidth (nm) & $\begin{array}{c}\text { Maximum } \\
\text { reflectance }\end{array}$ & $\begin{array}{c}\text { Signal to noise } \\
\text { ratio }\end{array}$ \\
\hline Land/cloud & 1 & $620-670$ & 1.49 & 128 \\
& 2 & $841-876$ & 1.00 & 201 \\
& 3 & $459-479$ & 1.04 & 243 \\
& 4 & $545-565$ & 0.93 & 228 \\
& 5 & $1230-1250$ & 0.51 & 74 \\
& 6 & $1628-1652$ & 1.02 & 275 \\
& 7 & $2105-2155$ & 0.81 & 110 \\
\hline Ocean color & 8 & $405-420$ & 0.33 & 880 \\
& 9 & $438-448$ & 0.23 & 838 \\
& 10 & $483-493$ & 0.17 & 802 \\
& 11 & $526-536$ & 0.15 & 754 \\
& 12 & $546-556$ & 0.12 & 750 \\
& 13 & $662-672$ & 0.08 & 910 \\
& 14 & $673-683$ & 0.07 & 1087 \\
& 15 & $743-753$ & 0.07 & 586 \\
& 16 & $862-877$ & 0.06 & 516 \\
\hline
\end{tabular}

GULF OF MARTABAN

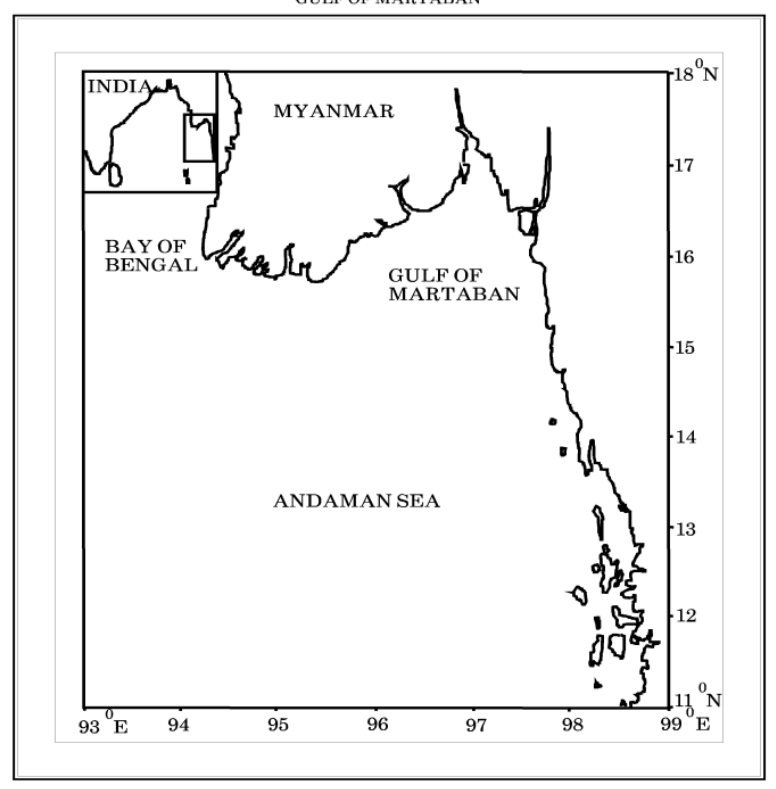

Figure 1. Study area 


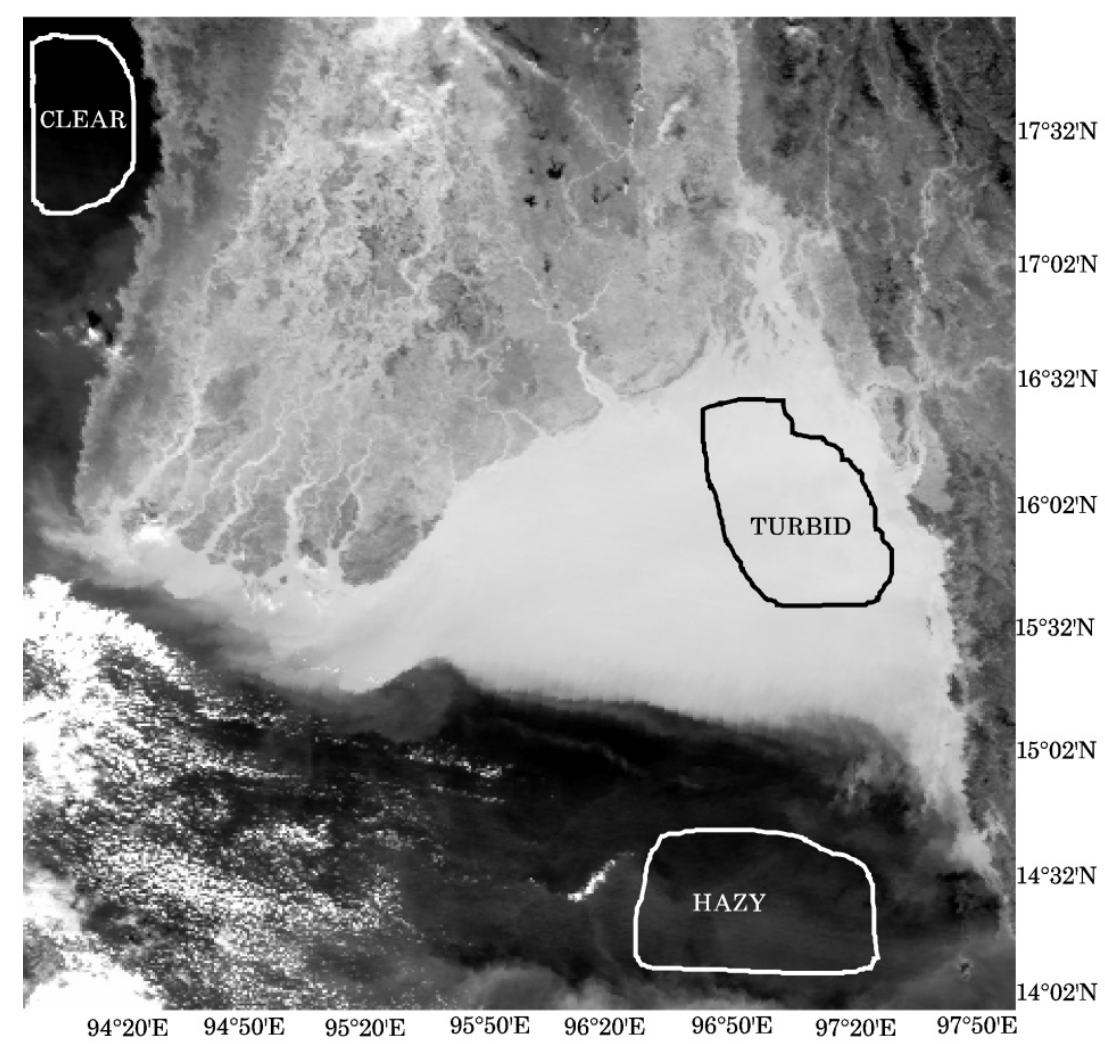

Figure 2. An image of MODIS $0.55 \mu \mathrm{m}$ channel for 13 November 2008 represents clear, hazy and turbid water areas.

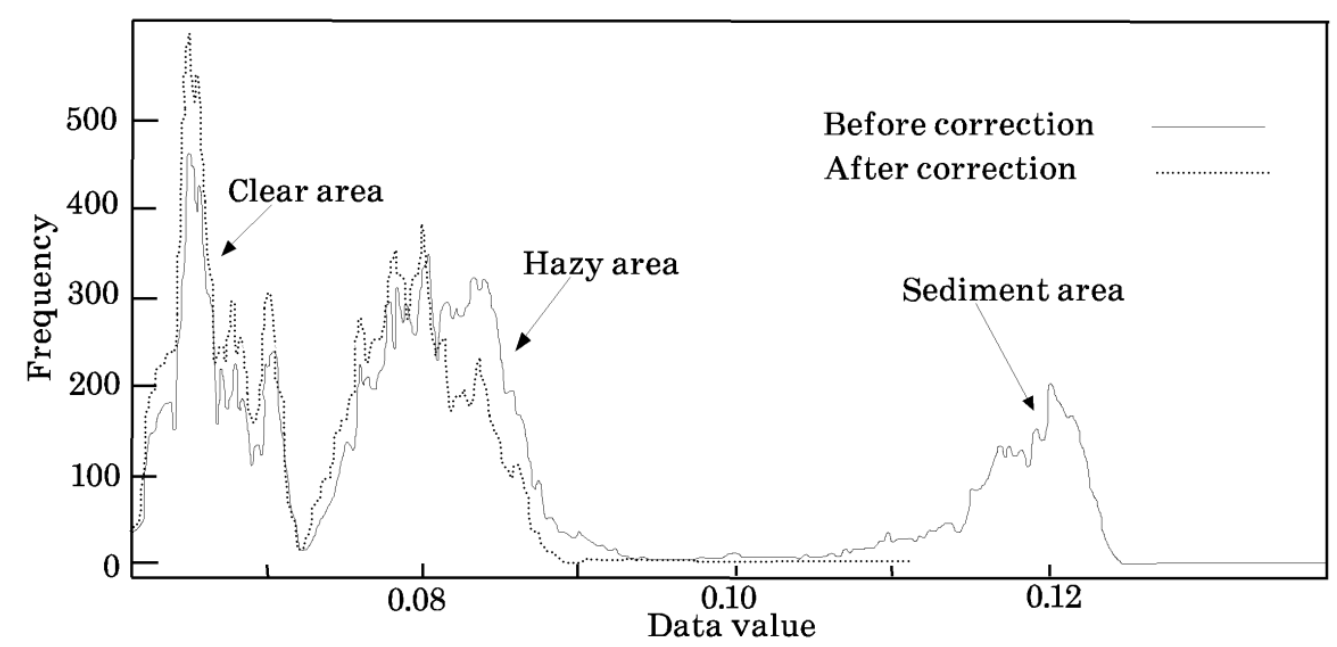

Figure 3. Histogram of clear, hazy and sediment influence areas. 


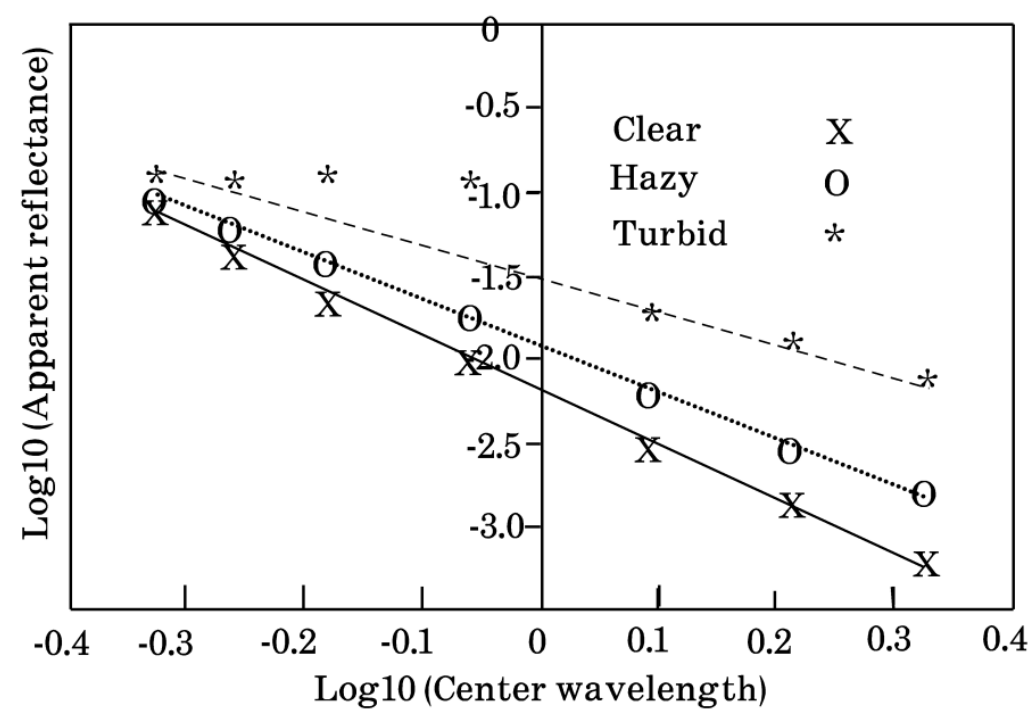

Figure 4. Log-log plot for clear, hazy and sediment area.

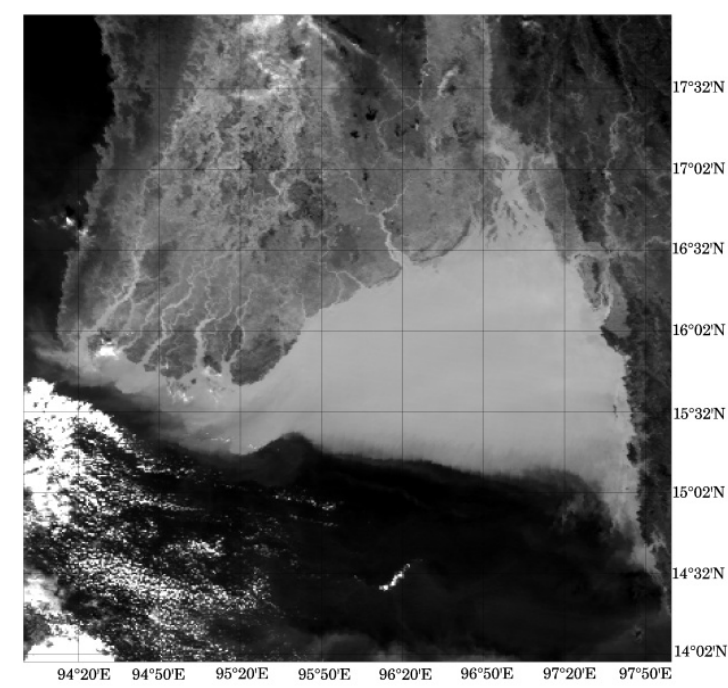

(a) 


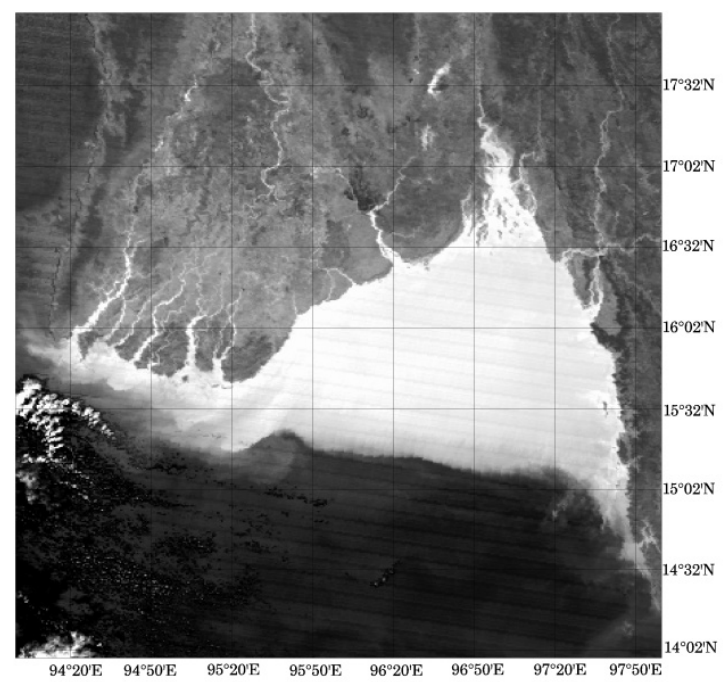

(b)

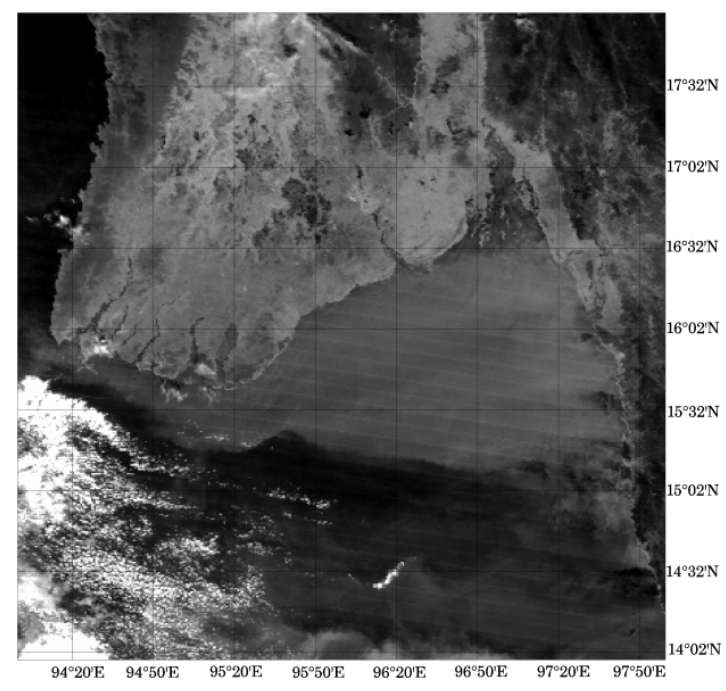

(c)

Figure 5. Image of 0.55 channel over Gulf of Martaban on 13 November 2008. (a) Image represents aerosol and sediment contribution. (b) Sediment contribution in the data. (c) Aerosol contributions after sediment reflectance were removed. 


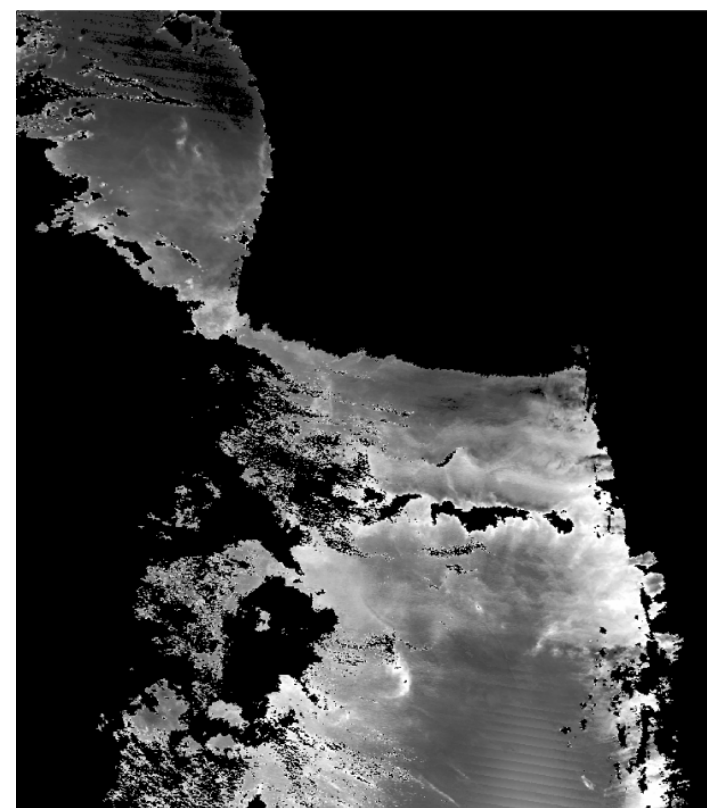

(a)

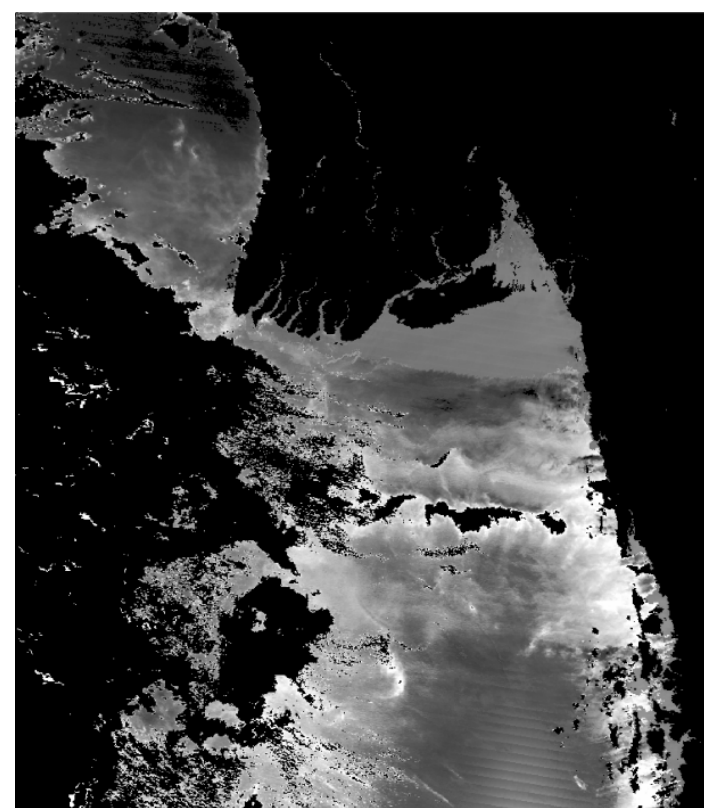

(b)

Figure 6. Aerosol optical depth map over Gulf of Martaban for the date of 13 November 2008. (a) AOD map of $0.869 \mu \mathrm{m}$ distributed by MODIS ocean color. (b) AOD of 0.869 produced by regression technique. 